strongly held opinions which exist on the subject of informed consent.

It was because members of the central Oxford research ethics committee recognised that so much unsubstantiated opinion existed on this matter that Dr Jennifer King was commissioned to conduct a systematic review of the available empirical evidence. Dr King's review has recently been published as a supplement to the Bulletin of the Institute of Medical Ethics. It concludes that there is a general tendency for doctors to underestimate the amount of information required by patients but that a flexible approach is required because the needs of individual patients vary greatly and a minority quite clearly do not wish to have detailed information about their disease and the ways in which it might be treated.

As editor of the Bulletin Dr Nicholson might have used the opportunity presented by publication of the study by Dr Simes and others to endorse Dr King's call for more empirical research on informed consent to treatment. As it is, Dr Nicholson and other medical ethicists continue to give the impression that it is inconceivable to them that authoritarian promotion of their opinions may actually compromise the best interests of patients. If medical ethicists wish to make it clear to others that they are neither naive nor arrogant about the possible consequences of their increasing power to influence clinical practice they must be seen to foster the empirical research which is required to investigate the effects on patients of their various prescriptions and proscriptions on informed consent and other matters.

IAIN CHALMERS

National Perinatal Epidemiology Unit,

Radcliffe Infirmary,

Oxford OX2 6HE

\section{Hazard of potassium chloride solution}

SIR,-In 1985 several of us made a plea for improved labelling and presentation of potassium chloride ampoules so that they would be clearly distinguishable from other solutions, especially sodium chloride. ${ }^{12}$ It was therefore particularly sad to note that a further death has now occurred because potassium chloride instead of sodium chloride had been injected through a drip. ${ }^{3}$

It is commendable that the West Midlands region has taken steps to prevent further mistakes by issuing potassium chloride ampoules with fixed plastic caps ( 3 January, p 54). However, measures are required which would have national and international impact: one such measure would be to make potassium chloride ampoules distinctive, in one way or another, at the time of manufacture. Manufacturers should accept the responsibility for this, and they are reminded that the need for change is greater than ever so that deaths from the inadvertent injection of potassium chloride become a thing of the past.

A much wider issue is also raised, however, about the administration of drugs, especially intravenously, by doctors in hospitals. In the United Kingdom, at least, a doctor is not required to check a drug with another member of staff before giving it. There is thus no safeguard against a basic error such as not reading the label, as happened in the latest tragedy. ${ }^{3}$ In many hospitals only doctors are permitted to give intravenous drugs and this burden falls on junior doctors, who may be overworked. There is therefore considerable potential for disaster, especially with insulin, chemotherapy, antibiotics, and cardiac drugs.

Nursing staff, by contrast, are required to double check a drug with another member of staff before giving it. This virtually eliminates the risk of a wrong drug being administered. Doctors should be required to follow this procedure too.

Department of Medicine,

M LAKHANI

Addenbrooke's Hospital

Cambridge CB2 $2 Q Q$

1 Lakhani M, Stewart WK. Hazards of potassium chloride solution. Lancet 1985; ii: 453 .

2 Rendell-Baker L, Meyer JA. Hazards of potassium chloride șolution. Lancet 1985; ii:329.

3 Anonymous. Doctor injected baby with deadly solution. Guardian 1986; Nov 29:4 (col 6).

\section{Junior staff and waiting lists}

SIR,-Although dermatology has a smaller inpatient commitment than many other specialties, the low level of junior staff numbers in dermatology, as shown by the table of ratios of juniors to consultants (3 January, p 68), is a very short sighted NHS policy.

Patients presenting with skin disease in genera practice outnumber most, if not all, other patients if you discount those with upper respiratory tract infections, which presumably would come under the care of the chest physician. By their own admission general practitioners are uncomfortable with skin diseases and this probably reflects their low exposure to them during their undergraduate and postgraduate training. This lack of exposure, thankfully, is gradually changing, but the impetus for improved general practitioner care of skin diseases could be greatly increased if dermatology became an essential part of GP rotation training schemes in hospital medicine.

In an election year waiting lists will be a sensitive issue, and the length of waiting lists for outpatient appointments for people with skin diseases varies greatly from district to district. A reasonable average would be about 18 weeks. Some districts have even closed their appointment books because new appointments are unavailable for 36 weeks. Patients are therefore diverted to neighbouring districts, who find their lists swelling as a result. On a recent television show Mrs Edwina Currie said that waiting lists of 20 weeks for routine skin appointments were unacceptable and remarked that she would like to hear of any district with such long lists. I suspect that she was inundated with letters from some, while others thought that she must have been a little out of touch with reality. - I believe there is no single specialty in which the outpatient waiting lists could be more easily reduced by expanding the number of junior doctors working with a consultant than in skin clinics. The current policy of expanding numbers of consultant dermatologists at the expense of numbers of junior staff will lead to a better quality of service in terms of diagnosis and management, but from the quantitative point of view there is no guarantee that there will be even a minimal reduction in the numbers of patients waiting to be seen.

Thus, from the point of view of both the future training of general practitioners and the more political aspect of the waiting lists I would urge general managers to take a more sympathetic view of requests from dermatologists for help in staffing their clinics.

Prince of Wales Hospital

C J O'DOHERTY London N15 4AW

\section{Updating the "Drug Tariff"}

SIR,-At regular intervals we receive thick slabs of paper which are amendments to the Drug Tariff. A lot of secretarial time is absorbed in inserting these amendments so that our copies are often $\underline{\underline{T}}$ unavailable for reference. The expense of this exercise to an impoverished Health Service must be enormous, and it is surely unnecessary 2 for general practitioners to have such detailed information updated so frequently. Would other $\Omega$ colleagues agree that an entirely new reprint of the $\bar{F}$ Drug Tariff, say twice a year, would be an ade- ग quate, sufficient, and cheaper alternative?

J P LESTER ?

$S$ A W TAYLOR A K HAIRE $\stackrel{0}{\rightarrow}$

Walsall, wS1 IUG A W NEWTON

\section{Points}

On the use of living kidney donors: a reply

Drs AARON SPITAL (University of Rochester School of Medicine, Rochester, NY 14621, USA) and Max $\frac{0}{3}$ SPITAL (Cornell Medical Center, White Plains, 3 NY 10605) write: We strongly disagree with the iN position recently adopted by the British Transplantation Society. 'The potential donor is now required to pass a long series of non-medical tests before he is allowed to give. It is as if the donor is assumed to be or psychotic or even criminal until proved innocent. N Firstly, we believe it is wrong to assign physicians the $\infty$ responsibility of administering and enforcing the long series of tests recommended; physicians are physicians, not policemen. Secondly, we have to ask $\mathbb{A}$ how often the occasion arises where the donor's motives are suspect and clandestine and the transplant team needs to agonise over his acceptance. Very seldom. Several studies have shown altruism to be the primary motive for donating, at least in the Western world. ${ }^{2}$ (And donors not only face risks but may $\vec{\bullet}$ also derive substantial psychological benefit from $\infty$ donating. ${ }^{3}$ ) The society's position is akin to mandating that all passengers of the Queen Elizabeth II wear life jackets all the time for fear someone might jump overboard. Lastly, we respect but differ from the position taken by the society that "the only justification for the use of living donors . . . is the continuing shortage of cadaveric donors." Most US transplant $\mathbb{D}$ centres consider living donors preferable to cadaver donors for several reasons, the most important being $O$ the superior results achieved. ${ }^{4}$ Let people take responsibility for themselves in this matter as they do in others, and let physicians get back to doing what they do best-taking care of the medical problems of their patients.

1 Sells RA, Johnson RWG, Hutchinson I. Recommendations on the use of living kidney donors in the United Kingdom. BrMed $f$ 1986;293:257-8.

2 Stiller CR, Lindberg MC, Rimstead D, et al. Living related donation. Transplant Proc 1985;17:85-100.

Spital A, Spital M. Donor's choice or Hobson's choice? Arch Intern Med 1985;145:1297-301.

4 Spital A, Spital M, Spital R. The living kidney donor: alive and well. Arch Intern Med 1986;146: 1993-6.

\section{Angioplasty and the need for angiography}

Dr J F ReIDY ( $X$ Ray Department, Guy's Hospital, N London SE1 9RT) writes: Dr W Bruce Campbell $O$ (25 October, p 1047) suggests that as many as two fifths of patients presenting with arterial disease of the leg may be suitable for percutaneous angioplasty $\mathbb{D}$ procedures. This made it all the more astonishing to read in the same issue ( $p$ 1086) Mr C P Sherman and 0 colleagues (appropriately in the For Debate column) advocating that only Doppler studies were necessary to make the decision whether to operate for femoropopliteal disease and then to decide which operation to $\mathbb{D}$ offer. As they advocate that angiography is unnecessary it follows that these surgeons see no need for angioplasty in their practice. One other major 8 criticism of this paper is the assumption that an adequate femoral pulse excludes important disease in the aortoiliac segment. We sometimes find it difficult, of as do others, ${ }^{12}$ to make this decision with angiography 